AUSTRALIAN JOURNAL OF BASIC AND APPLIED SCIENCES

ISSN:1991-8178

EISSN: $2309-8414$

DOI: 10.22587/ajbas.2017.11.13.2

Journal home page: www.ajbasweb.com

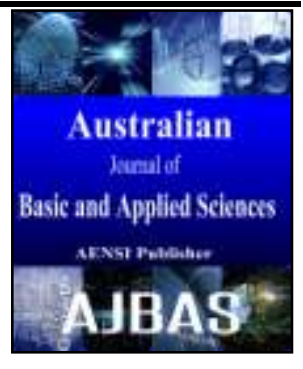

\title{
Climate Change And Health Of The Aged In Lagos, Nigeria
}

\author{
${ }^{1}$ Aina Thompson Adeboyejo and ${ }^{2}$ Yemi Adewoyin \\ ${ }^{I}$ Department of Urban and Regional Planning, Ladoke Akintola University of Technology, Ogbomoso, Nigeria. \\ ${ }^{2}$ Department of Geography, University of Nigeria, Nsukka, Nigeria.
}

\section{Address For Correspondence:}

Yemi ADEWOYIN, University of Nigeria, Department of Geography, Faculty of the Social Sciences, University of Nigeria, Nsukka, 4100001, Nigeria.

E-mail: yemiadewoyin@yahoo.com

\section{ART ICLE INFO}

\section{Article history:}

Received 19 August 2017

Accepted 1 November 2017

Available online 11 November 2017

Keywords:

Climate Change, Climate-Related Diseases, Aged People

\begin{abstract}
A B S T R A C T
Background: The aged cohort is more susceptible to ill-health owing to their physiological and immunological compositions. Their lifestyles, nutritional status and conditions to which they are exposed in their social and physical environments matter for their health. Conditions in the physical environment, particularly those related to climatic elements,have the propensity to aggravate health challenges among this cohort through their exposure to weather extremities and fluctuations in temperature and rainfall. Objective: Against this background, this paper examines the effects of climate change on the trend and prevalence of climate-related diseases among the aged in an urban setting using Ikeja, Lagos, Nigeria as a case study. Two sets of secondary data; hospital records of 600 adults aged 50 and above with clinically-diagnosed cases of climate related diseases, and data on climatic parameters of temperature and rainfall, were employed for the study. The data sets were collected for the period 2001 to 2015 . Results: Temperature declined over the period of study while rainfall increased. The study also showed that incidence of high blood pressure was more prevalent $(43 \%)$ than any other climate-related diseases among the sampled population. This was followed by fever and respiratory diseases. Incidences of cholera and diarrhea as well as blindness, and skin diseases were relatively fewer. The cases of high blood pressure, fever and respiratory diseases were positively correlated with year as they showed a progressive annual increase in relation to the fluctuations in rainfall and temperature, particularly increased rainfall. The result of the regression analysis $\left(\mathrm{R}^{2}=0.115\right)$ also shows that the fluctuations in rainfall and temperature accounted for $11.5 \%$ of the variations in climate-related diseases among the aged in the period studied. Conclusion: With the observed effects of climate change on the blood pressure of the aged as well as on the prevalence of fever and respiratory diseases among them, this study is suggesting that emphasis should be placed on social inclusiveness and financial independence for the elderly in order for them to adequately adapt to the vagaries of climate change.
\end{abstract}

\section{INTRODUCTION}

In the last few decades, issues of climate change have featured prominently in the discussions on the health of cities and their inhabitants largely because cities are the major contributors of greenhouse gases responsible for global warming, and also house more than $50 \%$ of world population. According to a World Bank report, cities consume as much as $80 \%$ of energy production worldwide and also account for an almost equal share of global greenhouse gas emissions (World Bank, 2010). These emissions come from anthropogenic activities like power generation, wastewater treatments, industrial activities, transportation, land-use change, deforestation and agriculture, as well as from residential and commercial domestic activities (World Bank, 2009; Chat Nyoung and Sentian, 2015; Abdrabbo et al, 2016; Torres et al, 2016). These activities, on a global scale, are responsible for climate change. The Environmental Protection Agency (EPA) of the United States of America describes climate change as major changes in temperature, precipitation, or wind patterns, among others, that occur over

Open Access Journal

\section{Published BY AENSI Publication}

(C) 2017 AENSI Publisher All rights reserved

This work is licensed under the Creative Commons Attribution International License (CC BY).

http://creativecommons.org/licenses/by/4.0/

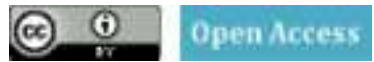

To Cite This Article: Aina Thompson Adeboyejo and Yemi Adewoyin., Climate Change And Health Of The Aged In Lagos, Nigeria. Aust. J. Basic \& Appl. Sci., 11(13): 8-16, 2017 
several decades or longer (EPA, 2016). The World Bank, following the Intergovernmental Panel on Climate Change (IPCC, 2007), defines climate change as a statistically significant variation in either the mean state of the climate or in its variability, persisting for an extended period, usually decades (World Bank, 2010).

Climate change has been found to have several negative consequences cutting across nearly all spheres of life, particularly urban livability and human health, either directly or indirectly (Abisha and Sasilatha, 2016; Malikabood et al, 2016; Sarry El-Din et al, 2012). This follows from its effects on both the social and environmental determinants of health such as clean air, safe drinking water, food, and shelter. In other words, while greenhouse gases emissions pollute the air, effluents discharge from homes and industrial site, and melting glaciers, rising sea levels and their attendant effects on flooding, make water unsafe for drinking.Glacier melting and rising sea levels are consequent upon global warming. Changing rainfall pattern and rising temperatures as well as deforestation impact food production while changing land-use and other natural disasters precipitated by human activities in the environment threaten safe shelter. According to the World Health Organization (WHO), around 250,000 additional deaths are projected to occur annually between the years 2030 and 2050 due to malnutrition, malaria, diarrhea and heat stress occasioned by climate change (WHO, 2015). Further, extreme hot temperatures have also been found to contribute directly to premature deaths and mental illness as well as deaths from cardiovascular and respiratory diseases (CDC, 2015; WHO, 2015), especially among the aged. The aged are particularly more at risk of climate-related diseases because of the effect of their age on their physiological and immunological compositions.

Carnes (2014) notes that the aged are more at risk of climate-related diseases because they have a lower physiological reserve, possess a slower rate of metabolism and a weakened immune system, and have a higher morbidity rate. They are therefore more sensitive to changes in the environment. Gamble et al. (2013) also found out that older Americans are likely to be more vulnerable to stressors associated with climate change based on the evidence of adverse effect of heat on their health. Schwartz (1994) and Schwartz and Morris (1995) equally found that periods of high levels of air pollution correlated with increased hospitalizations for cardiovascular and lung diseases among older persons in America. Filliberto et al. (2010) attribute the many negative health effects of climate change on older people to their physiological susceptibility and social vulnerability while Geller and Zenick (2005) suggested that pre-exposure health status, psychological wellbeing and social characteristics of the elderly should form the basis for assessing the health impacts of environmental changes on the elderly.

This paper investigates the effect of climate change on the trend and prevalence of climate-related diseases among the aged in Lagos, Nigeria. While age 65 has been commonly accepted as a definition of elderly or older persons in the developed world, the United Nations' cut-off is age 60 to coincide with the age at which the pension benefits are paid in most countries of the world (WHO, 2016). Akaneme et al (2016) also see selfperception as a determinant of what 'old' means. In this study however, people from age 50 are categorized as aged. The choice of 50 is predicated upon two major factors. Life expectancy in Nigeria oscillated between 47 and 54 between the year 2011 and 2015. It was lower in the preceding years. This implies that average Nigerians die around the age of 50 and using a higher benchmark for the research would reduce the study population. The choice of 50 is also to align with the adoption of age 50 as the cut-off for measuring the aged in Africa by the World Health Organization (WHO) in its Minimum Data Set (MDS) project based on the peculiarity of the African cultural settings (WHO, 2016a).

\section{Methodology:}

Lagos, the study area, is the commercial capital of Nigeria and also a former administrative capital city of the country. Based on the 2006 National Population Census, the state was projected to have over $10.6 \mathrm{~m}$ inhabitants in 2011 (NBS, 2012). The population is spread across 57 Local Council Development Areas (LCDAs) and broadly between localities in Lagos Mainland and Lagos Island. Ikeja, in Lagos Mainland, was purposively sampled for this study because of its unique characteristics as an urban agglomeration. Apart from having one of the largest industrial estates in Nigeria, with an equally large quantum of greenhouse gases emission and industrial effluents discharges, it also houses the Murtala Mohammed International Airport, the busiest airport in Nigeria in terms of air trafficand number of airplanes. Jet fumes contribute immensely to global warming. The seat of the Lagos State government is also in Ikeja and it has several residential districts ranging from the government reserved and the high-brow areas of Opebi and Adeniyi Jones, among others, to the high density areas adjoining Agege, Mushin and Oshodi. Ikeja thus have a localized climate that would impact directly on its population.

For the study, two sets of secondary data were employed. These are hospital records and climatic parameters of rainfall and temperature. The climatic data (mean maximum temperature and mean annual rainfall) were sourced from the Nigerian Meteorological Agency (NIMET), Ikeja Station for the years 2001 to 2014 while a total of 600 case files of adults aged 50 and abovewith clinically-diagnosed cases of climaterelated diseases resident in Ikeja, between 2001 and 2014 were reviewed from the Lagos State University Teaching Hospital (LASUTH), Ikeja. The climate-related diseases reviewed are those affecting the lungs; 
asthma, bronchitis and pneumonia, febrile illnesses; malaria, typhoid, yellow fever and dengue fever, waterborne diseases; cholera and diarrhea as well as heart (high blood pressure), skin and eye diseases with environmental prognosis. The impacts of temperature and rainfall variations on diseases are well documented in the literature (Adeboyejo et al., 2012; Gamble et al., 2013; Adewoyin, 2015 for instance).

The climatic data and data on clinically-diagnosed cases of climate-related diseases were projected to 2015 using simple linear projections and analyzed for trends using the Pearson Product Moment Correlation (PPMC) statistical technique. Both data sets were subsequently related to each other using the Multiple Linear Regression statistical analysis to determine the amount of variations in prevalence of the sampled climaterelated diseases explained by climate change. Graphs and tables were used copiously for illustrations.

\section{RESULTS AND DISCUSSIONS}

\section{Climatic Trend:}

Between 2001 and 2015, the mean annual rainfall in Ikeja was $135.7 \mathrm{~mm}$ per annum. The lowest amount of precipitation, $115 \mathrm{~mm}$, was recorded in 2010 while the following year, 2011 had the highest amount of precipitation at almost $175 \mathrm{~mm}$. In the years 2001 to 2006, all annual precipitation volumes were lower than $135.7 \mathrm{~mm}$ except in 2004 when it was $141.1 \mathrm{~mm}$. In the following years, the annual amount of rainfall exceeded $135.7 \mathrm{~mm}$ except for years 2009 and 2010 when the least volumes for the period under review were recorded. Figure 1 illustrates the trend of climatic parameters in Ikeja between 2001 and 2015. A further analysis of the rainfall pattern shows that annual volume of rainfall in Ikeja, though fluctuating, has been on the increase over the years. A correlation analysis on the trend confirms that the annual volume of rainfall is positively correlated $(\mathrm{r}=0.384)$ with years. This implies that as the years go by, rainfall volume increases. The temperature pattern is however different.

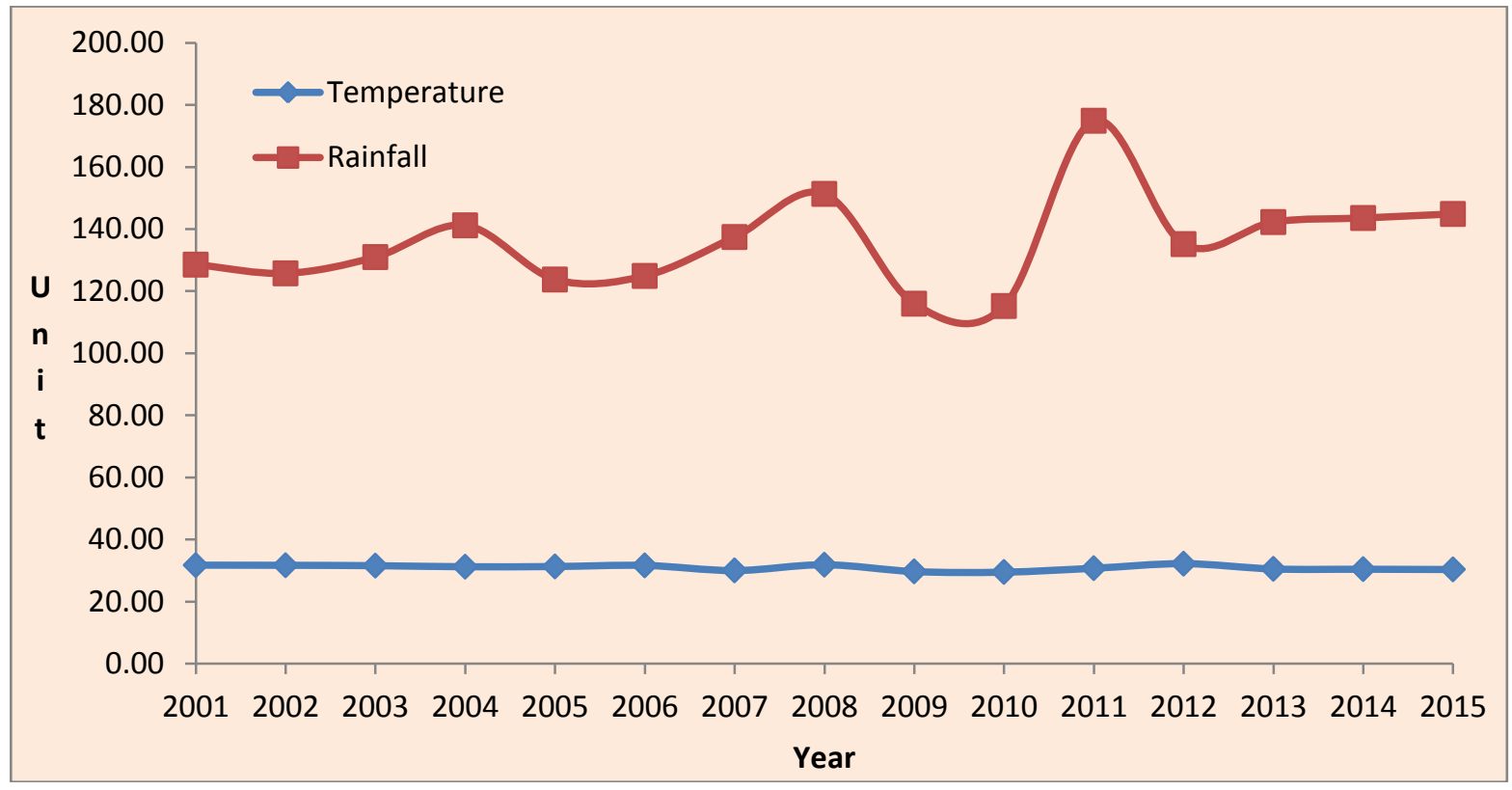

Fig. 1: Trend of Rainfall and Temperature in Ikeja (2001 - 2015)

Source: Authors' Analysis from NIMET's Records, 2016

The mean maximum temperature was as high as $31.72^{\circ} \mathrm{C}$ in 2001 , well above the period average of $30.97^{\circ} \mathrm{C}$. Up until the year 2007 , no mean maximum temperature reading for Ikeja was less than the period average, instead they oscillated between $31.22^{\circ} \mathrm{C}$ and $31.72^{\circ} \mathrm{C}$. The years $2001-2006$ were therefore hotter in the study area. Year 2007 provided a temporary reprieve with a temperature of $30.03^{\circ} \mathrm{C}$ as the temperature climbed back to $31.85^{\circ} \mathrm{C}$ in 2008 before lower mean maximum temperature readings were recorded for almost all the succeeding years except 2012 as illustrated in Figure 1. In contrast with the rainfall situation, temperature has been declining in the study area. The analysis of the trend reveals a correlation coefficient (r) of -0.468 , indicating that year after year, Ikeja has been experiencing a less hot temperature. This may be attributable on the one hand to the more precipitation witnessed (as shown earlier) and their cooling effects on the local climate, and a possible decline in greenhouse gases emissions from the industrial district of the study area on the other hand. The local economy has witnessed the closure and / or relocation of several manufacturing industries in the 
last couple of years for so many reasons and this, would have a positive effect on the local heat island in terms of reduced emissions.

\section{Disease Prevalence:}

From the reviewed case files, related diseases were grouped to come up with the six climate-related diseases analyzed in this study. All febrile diseases, malaria fever, typhoid fever, yellow fever and dengue fever, were grouped as fever as they present same symptoms, are vector-based, and are usually treated by selfmedication at home in Nigeria before escalation of symptoms force hospital visits where proper diagnosis are carried out to separate them. Asthma, Bronchitis, Pneumonia and other upper respiratory infections and diseases were grouped as respiratory diseases while Diarrhea, which could be caused by food poisoning, drinking infected water/fluid, worms, or a symptom of Cholera is grouped with Cholera as digestive diseases. Both Cholera and Diarrhea are temperature-sensitive bacterial diseases. Cases of blindness, high blood pressure and skin diseases were treated as presented.

Cases of high blood pressure were most prevalent among the aged in Ikeja as these accounted for about $43 \%$ of the cases reviewed between 2001 and 2015. This implies that the elderly suffer more from heart conditions than any other disease as they age. Research has also shown that between $30 \%$ and $50 \%$ of elderly people suffer from high blood pressure (Applegate, 1989; WHO, 2016b). Cases of febrile illnesses ranked second in prevalence among the sampled population. They accounted for about $21 \%$ of the diseases treated at the LASUTH among the aged in the period under review. Unlike children, especially under the age of 5, cases of malaria and other febrile illnesses among the adults are relatively lower because the adults have a higher level of cognitive development and can prevent themselves from exposure to disease causing conditions. Respiratory diseases among the aged constituted $17 \%$ of the cases reviewed while blindness and digestive diseases were $8 \%$ and $6 \%$ respectively.Skin diseases accounted for $5 \%$ of the diseases. Hot temperature and air pollution aggravates respiratory problems and rainfall increases the growth rates of pollens that, when inhaled, cause irritation of the lungs and air ways. Cholera-causing bacteria and the human skin are also temperature sensitive. Hot temperature also causes dryness that impacts wind direction and intensity thereby causing blindness when the eyes are unduly exposed. The proportion of the diseases is shown graphically in Figure 2.

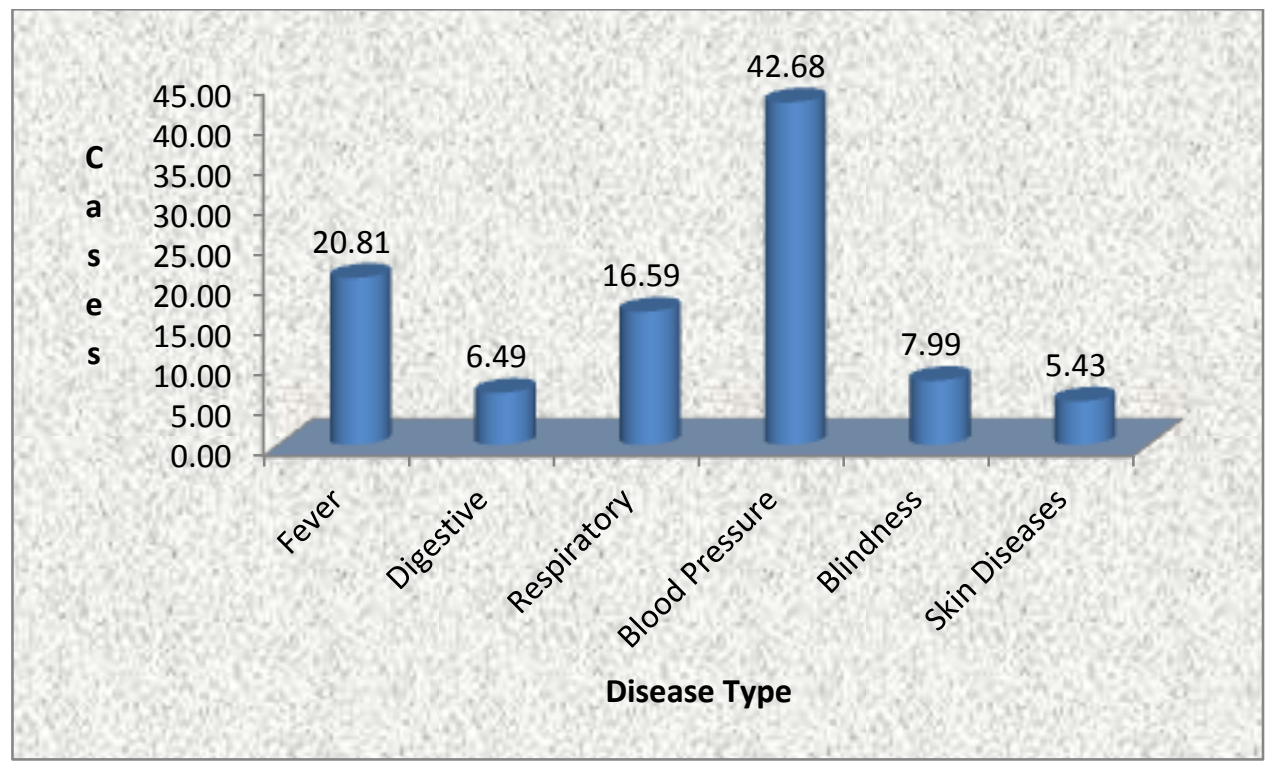

Fig. 2: Proportion of Climate-Related Diseases among the Aged in Ikeja (2001 - 2015)

Source: Authors' Survey, 2015

\section{Temporal Trends of Diseases:}

Reported cases of fever were lowest in 2009 and highest in 2003 with 3 and 22 cases respectively. Less than 10 cases were recorded annually in 8 of the 15 years reviewed. In the other 7 years, the number of cases ranged from 11 to 22. In 2003 when the highest number of cases was recorded, temperature in the study area was higher than the period average while rainfall was lower than the average. Both temperature and rainfall were well below the recorded average in 2009 when the cases of fever were just 3 . In the same 2009, no single case of Cholera and Diarrhea was recorded, ditto for the years 2004 and 2012. The highest number of digestive disease recorded was 8 in 2008, followed by 6 in 2014 and 5 apiece in 2002 and 2006. Years 2008, 2006 and 2002 were very hot in Ikeja with temperatures over $31.64^{\circ} \mathrm{C}$ and fewer rainfalls. For respiratory diseases, 32 cases were 
recorded in 2010, followed by 17 and 13 cases in 2014 and 2015 respectively. In the other years, the number of cases ranged from nil in 2006 and 2007 to 9 in 2012. Again, the very high number of cases in 2010 might not be unconnected with the fact that 2010 had the lowest mean maximum temperature in the period reviewed. Precipitation was also lowest in 2010. Lagos, being a coastal city, may have therefore experienced a more humid weather in 2010. Dampness precipitates upper respiratory disorders. The trend of diseases in Ikeja for the period 2001 to 2015 is depicted in Figures 3 and 4.

In 2014, 39 cases of high blood pressure were recorded and the figures were not less than 11 in any of the years except in 2001, 2006 and 2009 when 5, 4 and 3 cases were reported respectively. Other very high numbers of cases ( $\geq 20)$ were recorded in 2004 (20), 2008 (29), 2010 (27), 2011 (21), 2012 (28) and 2015 (28). Cases of high blood pressure therefore seem to be an all season affair. In 2014 when the highest number of cases was recorded however, the mean maximum temperature was lower than the period average while rainfall was well higher than the average indicating a colder year. Colder temperature causes the arteries to shrink and therefore makes the heart to do extra work in supplying blood to the body. Apart from the year 2010, cases of blindness and eyes related problems ranged from nil in 2009, 2011 and 2012 to 6 in 2008. There were 19 reported cases of blindness and eyes related diseases in 2010, a relatively humid year in the period reviewed with temperature and rainfall being below the period average. The high number of cases recorded may therefore be a manifestation of eye infections contracted in the preceding hotter and drier years 2001 to 2008. The incidence of skin diseases was highest at 8 in 2011 followed by 7 in 2005 and was between 0 and 4 in the other years. Year 2005 was hotter and drier while rainfall was highest in 2011. Rainfall and associated puddles encourage the proliferation of insect breeding habitats.

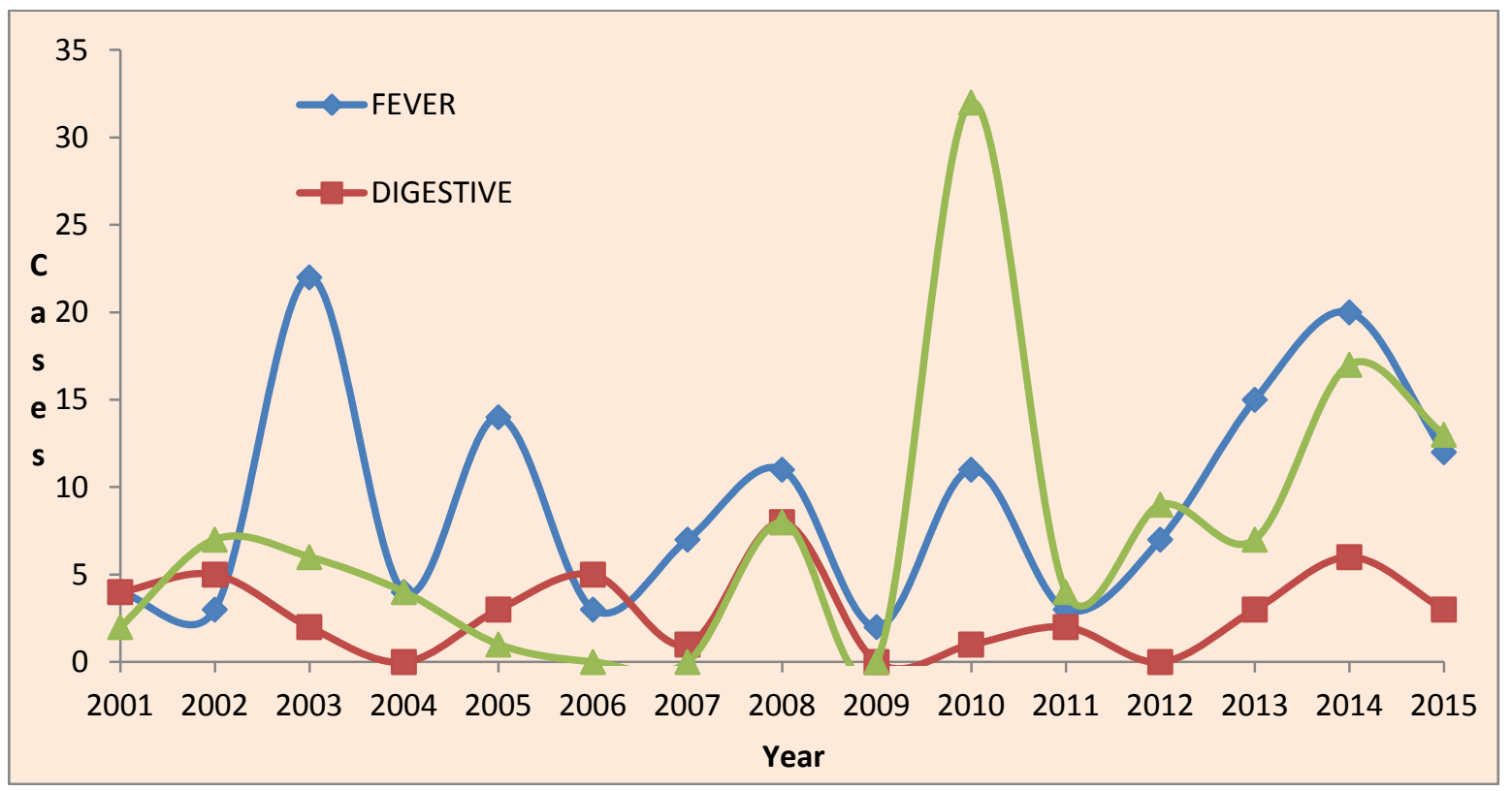

Fig. 3: Trend of Fever, Digestive, and Respiratory Diseases in Ikeja (2001 - 2015) Source: Authors' Survey, 2015 


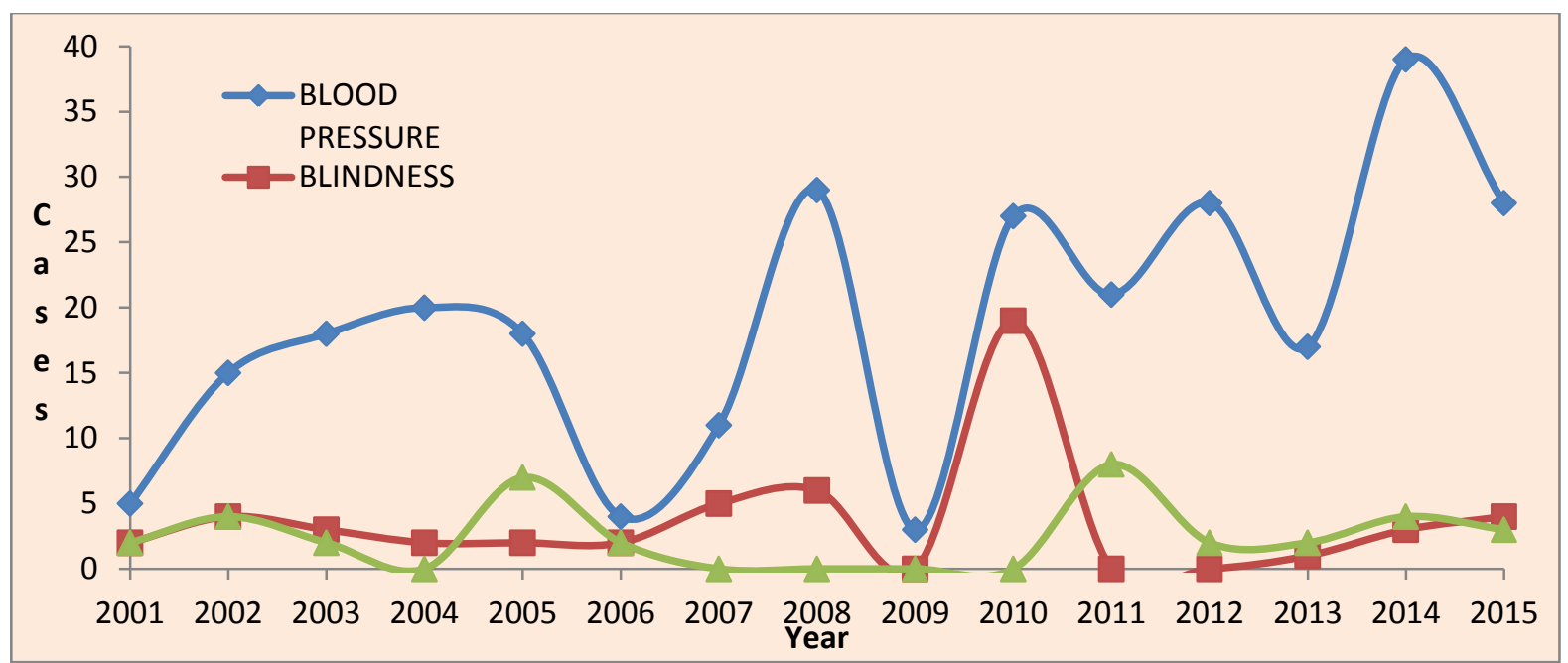

Fig. 4: Trend of Blood Pressure, Blindness and Skin Diseases in Ikeja (2001 - 2015)

Source: Authors' Survey, 2015

A correlational analysis to assess the relationship between the patterns of disease prevalence and year was carried out on the diseases individually and collectively. The essence was to determine the underlying trend based on the yearly variations in the climatic parameters in the study area. Apart from cases of high blood pressure, all other diseases returned statistically insignificant correlations (Table 1). Although fever, respiratory diseases and blood pressure showed a positive correlation indicating that as the years go by, cases of these diseases have been increasing, the results are not statistically significant except in the case of high blood pressure $(\mathrm{r}=0.446, \mathrm{P} \leq 0.05)$. This implies that changes in climatic parameters as recorded over the years in the study area influence the prevalence of fever, respiratory diseases and high blood pressure in the study area. There were no (near zero) correlations in the yearly incidence of blindness, skin diseases and digestive diseases viz-a-viz the yearly changes in climatic parameters however. Jointly, the cases of climate-related diseases sampled showed a positive correlation $(\mathrm{r}=0.481)$ over the years implying that the number of cases have been increasing steadily from year 2001 (Figure 5).

Table 1: Table of Correlations of Yearly Trend of Diseases
\begin{tabular}{|l|l|l|l|l|}
\hline S/N & Disease & Correlation Coefficient (r) & Level of Significance (P) & Remarks \\
\hline 1 & Fever & 0.280 & 0.312 & Not Significant \\
\hline 2 & Digestive & -0.054 & 0.850 & Not Significant \\
\hline 3 & Respiratory & 0.446 & 0.096 & Not Significant \\
\hline 4 & Blood Pressure & 0.586 & 0.022 & Significant at 0.05 \\
\hline 5 & Blindness & 0.045 & 0.874 & Not Significant \\
\hline 6 & Skin & 0.089 & 0.751 & Not Significant \\
\end{tabular}

Source: Authors' Computation, 2016

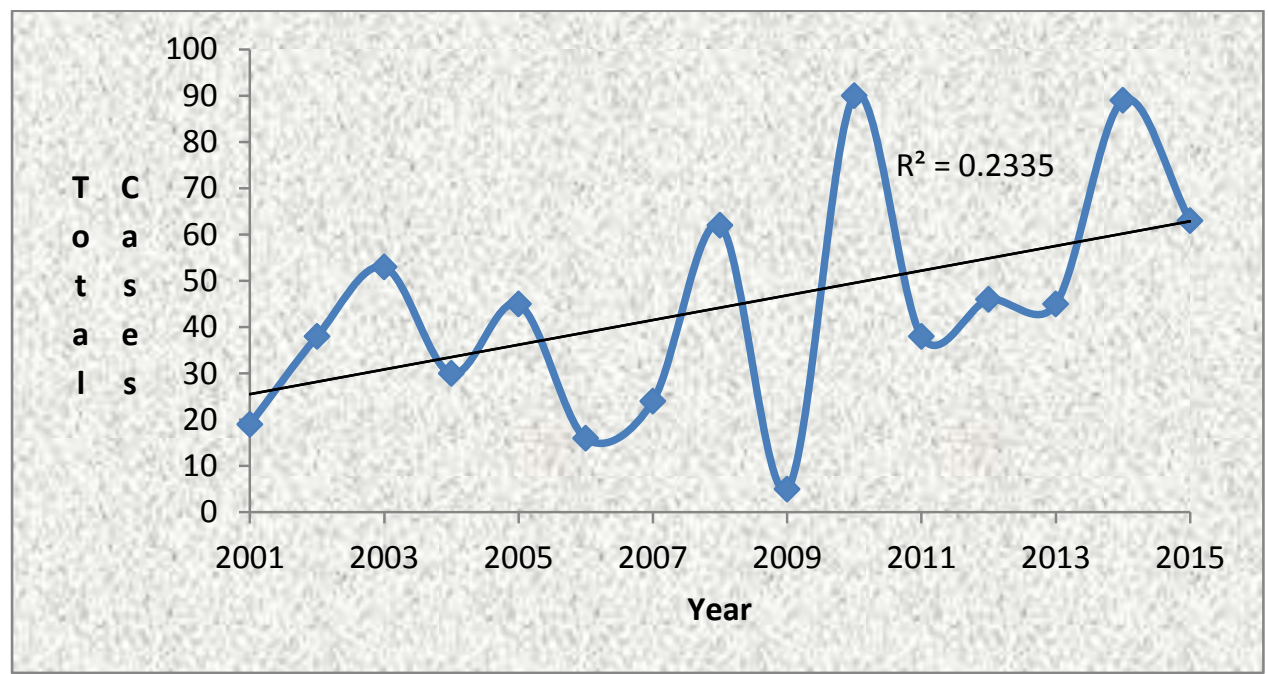

Fig. 5: Trend of All Climate-Related Diseases in Ikeja (2001 - 2015)

Source: Authors' Analysis, 2016 


\section{Climate Change and Variation in Diseases Prevalence:}

To determine the amount of variation in the prevalence of the climate-related diseases sampled between 2001 and 2015 attributable to climate change, a Multiple Linear Regression analysis was carried out with the annual total number of diseases cases as the dependent variable and annual mean maximum temperature and mean annual rainfall as the independent variables. Prior to the analysis, the absolute values of both temperature and rainfall were converted into their logarithmic equivalents to standardize the values and reduce the between group variance relative to the absolute number of diseases cases.

From the analysis, only $11.5 \%(R=0.115)$ of the variations in diseases prevalence was accounted for by the yearly change in climatic parameters. This implies that much as there were noticeable yearly variations in both temperature and rainfall in the study area, the variations were not sufficiently responsible for the variations in the pattern of prevalence of the climate-related diseases sampled for the period of study. In other words, apart from climate change, other factors are equally responsible for the variations. These may include both social and economic indices like age, family status, literacy and access to healthcare facilities, income, and local economic conditions among others. Also, the result was not statistically significant $(P \geq 0.05)$. From the analysis too, the contributions of the yearly variation in rainfall pattern were higher than the impacts of temperature in the variations in disease pattern. Rainfall had a Beta Coefficient of 0.339 while it was 0.029 for temperature. The fluctuation in rainfall pattern is therefore of more consequence as an environmental factor affecting the prevalence of climate-related diseases in the study area.

\section{Conclusion:}

From the foregoing, it has been shown that there are yearly changes in the climatic parameters of the study area with rainfall increasing by the year while temperature is on the decline. The temperature decline (an average annual mean maximum of about $31^{\circ} \mathrm{C}$ ) is relative to previous years and not indicative of a cooler climate however. The study also showed that incidence of high blood pressure was more prevalent (43\%) than any other climate-related diseases among people older than 50 in Lagos between 2001 and 2015. This was followed by fever and respiratory diseases. Incidences of cholera and diarrhea as well as blindness, and skin diseases were relatively fewer. The cases of high blood pressure, fever and respiratory diseases were positively correlated with year as they showed a progressive annual increase in relation to the fluctuations in rainfall and temperature, particularly increased rainfall. The regression analysis equally showed that while climate change accounted for about $12 \%$ of the variations in the prevalence of climate-related diseases in the study area between 2001 and 2015, the contributions of fluctuations in the amount of precipitation were higher. These findings are not largely different from those of Schwartz (1994), Schwartz and Morris (1995), Filliberto et al (2010) and Gamble et al (2013).

With the observed effects of climate change on the blood pressure of the aged as well as on the prevalence of fever and respiratory diseases among them, this study is suggesting that emphasis should be placed on social inclusiveness and financial independence for the elderly in order for them to adequately adapt to the vagaries of climate change. Such measures as enhanced access to healthcare, both in distance and cost, community health insurance (Soemarno et al, 2016), adequate and protective shelter, and prompt payments of pensions among others are recommended to aid the adaptation of the aged to the effects of climate change. In Nigeria today, the government is the largest employer of labour and the bulk of the aged population were once employees of the government whose major source of income after retirement is the monthly pension. Pension payment in the country is characterized by a high degree of irregularity, and relative to inflation rate and purchasing power, the amounts are paltry and are barely enough to meet the basic needs of the aged. If healthcare and shelter are made available and affordable, and the pensions are regular, the levels of susceptibility and exposureto disease causing conditions are reduced and health of the aged is enhanced.

Much of the damage done to the environment and responsible for climate change and variability are largely irreversible and their effects will continue to have implications for health and well-being of the population. Environmental issues are also trans-boundary in nature and damage in one location can have impacts in other locations. Cutting down on the emission of greenhouse gases in Ikeja, by relocating the industries or the airportfor instance, will only transfer the burden to other locations with impacts for those locations and some other locations as well. It is therefore important to scale up the level of awareness of the implications of human activities on the environment and the multiplier effects of such activities for urban livability as well as on health and well-being of the population. This study has been able to show that the elderly in urban Nigeria are negatively affected by changes in climatic elements, with these mostly affecting their cardiovascular system. With this knowledge, age specificity is of consequence in change communication and in other policy dictates and practices geared towards climate change control and adaptation among the population. 


\section{REFERENCES}

Abdrabbo, M.A.A., S.M. Saleh and A.A. Farag, 2016. Water Requirements for Maize under Climate Change, Journal of Applied Sciences Research, 12(5).

Abisha, M. and T. Sasilatha, 2016. Abnormality Analysis of Lungs Using External Parameters of Gross Segmentation, Australian Journal of Basic and Applied Sciences, 10(1)

Adeboyejo, A.T., M. Lirvhuwani and D.K. Shonisani, 2012. Impact of Climate Change on Children's Health in Limpopo Province, South Africa . International Journal of Environmental Research and Public Health, (9).

Adewoyin, Y., 2015. Analysis of Spatial and Temporal Patterns of Malaria Prevalence in Ibadan, Nigeria. Unpublished Ph.D. Thesis, Ladoke Akintola University of Technology, Ogbomoso, Nigeria.

Akaneme, I.N., E.N. Nwosu, C. Eseadi, L.N. Onuigbo, I. Ugwuafor and C.O. Onwurah, 2016. SelfPerceptions of Ageing, Problems and Coping Strategies among Older People with Special Needs, Journal of Applied Sciences Research, 12(3).

Al-Tell, Y., M. Allan and N. Al-Zboun, 2017. Investigating Perceived Leisure Constraints for Senior Tourists in Jordan, Australian Journal of Basic and Applied Sciences, 11(2).

Applegate, W.B., 1989. Hypertension in Elderly Patients. Annals of Internal Medicine, p: 10.

Carnes, B.A., 2014. Impact of Climate Change on Elder Health. Journal of Gerontology, 69: 9.

Centers for Disease Control and Prevention, 2015. Climate Change and Public Health - Climate Effects on Health. http://www.cdc.gov/climateand health/effects/ Accessed on 07/04/2016

Chan Nyoung, A.Y. and J. Sentian, 2015. Climate Change Impacts on Hydroxyl Radical (OH) from the CiTTyCAT Tropospheric Chemistry Model Simulations. Australian Journal of Basic and Applied Sciences, $9(32)$

Environmental Protection Agency, 2016. Climate Change: Basic Information. https://www.3.epa.gov/climatechange/basics/ Accessed on 07/04/2016

Filliberto, D., E. Wethington, K. Pillemer, L.M. Wells, M. Wysocki and J. True, 2010. Older People and Climate Change: Vulnerability and Health Effects. American Society on Aging. http://www.asaging.org/blog/older-people-and-climate-change-vulnerability-and-health-effects/ Accessed on $07 / 04 / 2016$

Gamble, J.L., B.J. Hurley, P.A. Schultz, W.S. Jaglom, N. Krishnan and M. Harris, 2013. Climate Change and Older Americans: State of the Science. Environmental Health Perspectives, 121: 1.

Geller, A.M. and H. Zenick, 2005. Aging and the Environment: A Research Framework. Environmental Health Perspectives, 113: 9

General Hospital Kediri. Australian Journal of Basic and Applied Sciences, 10(9).

Intergovernmental Panel on Climate Change, 2007. Summary for Policymakers. In Solomon, S., Qin, D., Manning, M., Z. Chen, M. Marquis, K.B. Avery, M. Tignor and H.L. Miller, (eds). Climate Change 2007: The Physical Science Basis. Cambridge, U.K, CUP.

Malikabood, F., R.J. Alwarid and L.J. Witwit, 2016. Estimation of Some Immunological Parameters among Chronic Periodontitis Patients with Cardiovascular disease. Australian Journal of Basic and Applied Sciences, 10(10)

National Bureau of Statistics, 2012. Social Statistics in Nigeria. Abuja; Government Press

Sarry El-Din, A.M., M. Erfan, W.A. Kandeel, et al., 2012. Prevalence of Prehypertension and Hypertension in a sample of Egyptian Adults and its Relation to Obesity, Australian Journal of Basic and Applied Sciences. 6(13)

Schwartz, J. and R. Morris, 1995. Air Pollution and Hospital Admissions for Cardiovascular Disease in Detroit, Michigan. American Journal of Epidemiology, 142.

Schwartz, J., 1994. Air Pollution and Hospital Admissions for the Elderly in Birmingham, Alabama. American Journal of Epidemiology, 139.

Soemarno, K., A. Setyo and L. Soleh, 2016. Protection of Public Health Services for the Poor in Gambian

Torres, P., L. Amaya and O. Ramos, 2016. Algorithm of Temperature Prediction for 2017 year in the Municipality of Cajicá, Journal of Applied Sciences Research, 12(12). 
World Bank, 2009. World Development Report 2010: Development and Climate Change. Washington, DC: The World Bank.

World Bank, 2010. Cities and Climate Change: An Urgent Agenda. Urban Development Series Knowledge Paper, 10. Washington.

World Health Organization, 2015. Climate Change and Health. Fact Sheet No 266. http://www.who.int/mediacentre/factsheets/fs266/en/ Accessed on 07/04/2016

World Health Organization, 2016a. Definition of an Older or Elderly Person. http://www.who.int/healthinfo/survey/ageingdefnolder/en/. Accessed 07/04/2016
World
Health
Organization,
2016 b.
Raised
Blood
Pressure.

http://www.who.int/gho/ncd/risk_factors/blood_pressure_prevalence_text/en/. Accessed 07/04/2016. 